\title{
SPL Drug Route of Administration Terminology
}

National Cancer Institute

\section{Source}

National Cancer Institute. SPL Drug Route of Administration Terminology. NCI

Thesaurus. Code C54455.

Terminology used for representation of the information on pharmaceutical product

route of administration in the framework of the Structured Product Labeling documents. 